\title{
A look at forensic dentistry - Part 2: Teeth as weapons of violence -
identification of bitemark perpetrators
}

\author{
D. Sweet, ${ }^{*}$ and I. A. Pretty, ${ }^{2}$
}

\begin{abstract}
Teeth are often used as weapons when one person attacks another or when a victim tries to ward off an assailant. It is relatively simple to record the evidence from the injury and the teeth for comparison of the shapes, sizes and pattern that are present. However, this comparative analysis is often very difficult, especially since human skin is curved, elastic, distortable and undergoing oedema. In many cases, though, conclusions can be reached about any role a suspect may have played in a crime. Additionally, traces of saliva deposited during biting can be recovered to acquire DNA evidence and this can be analyzed to determine who contributed this biological evidence. If dentists are aware of the various methods to collect and preserve bitemark evidence from victims and suspects it may be possible for them to assist the justice system to identify and prosecute violent offenders. This paper reviews the recognition and recovery of this evidence and provides insight into modern methods used to investigate bitemark evidence from heinous crimes.
\end{abstract}

$\mathrm{I}$ n mortal combat situations, such as the violence associated with life and death struggles between assailants and victims, the teeth are often used as a weapon. Indeed, using the teeth to inflict serious injury on an attacker may be the only available defensive method for a victim. ${ }^{1}$ Alternatively, it is well known that assailants in sexual attacks, including sexual homicide, rape and child sexual abuse, often bite their victims as an expression of dominance, rage and animalistic behaviour. ${ }^{2}$ The teeth are a significant component of our natural arsenal. It is suspected that many dentists have seldom considered their patients' teeth as such effective weapons! The aim of this paper is to provide information about this form of forensic evidence and to demonstrate how human

\footnotetext{
${ }^{1 *}$ Director, Bureau of Legal Dentistry, University of British Columbia, Canada; ${ }^{2}$ Doctoral Candidate, University of Liverpool, UK

${ }^{*}$ Correspondence to: David Sweet, 146-2355 East Mall, University of British Columbia, Vancouver, BC, Canada V6T 1Z4

email:dsweet@interchange.ubc.ca

REFEREED PAPER

Received 21.03.00; Accepted 24.07.00
}

(C) British Dental Journal 2001; 190: 415-418 bitemarks are used by courts to answer important questions that may arise during the prosecution of accused suspects.

Currently, there is no agreement among forensic odontologists about the individuality (uniqueness) of the dentition or the behaviour of human skin during biting. Although these issues have never been proven scientifically, much research is currently underway in an attempt to prove the suspicion that each human dentition is unique. The sizes, shapes and pattern of the biting edges of the anterior teeth that are arranged in the upper and lower dental arcades are thought to be specific to that individual. This is mainly caused by the sequence of eruption of anterior and poste-

In brief

- Bitemarks may be found on victims of violent crimes

- General practitioners may witness bitemarks on their patients

- Bitemarks are often complex wounds that require expert analysis

- Bitemarks are sources of both physical and biological evidence rior teeth. Canines must force their way into the dental arch, which often results in bodily movement, rotation and displacement of other teeth. The resulting configuration of the dentition produces an identifiable pattern that may be compared with similar patterns found on bitten objects to determine the likelihood that a specific individual has left their calling card.

The amount and degree of detail recorded in the bitten surface may vary from case to case. And, even if it is assumed that the dentition is individual enough to warrant use in forensic contexts, it is not known if this individuality is recorded specifically enough in the injury. In situations where sufficient detail is available, it may be possible to identify the biter to the exclusion of all others. Perhaps more significantly, it is possible to exclude suspects that did not leave the bitemark. $^{3}$

The authors contend that every member of the dental office team - from the receptionist and chairside assistant to the dentist should become familiar with the appearances and presentations of bitemark evidence. These injuries are often associated with physical and sexual abuse of children, spouses and elders. Moreover, the evidence is usually easily observed in the dental office during regular patient visits. Recognition and reporting of such injuries to specific authorities that are equipped to investigate such suspicions may end the episodic pattern of abuse and stop the cycle of violence from which many victims are not able to escape. ${ }^{4}$

When a consultant in paediatric medicine examines a young patient, who is a potential victim of domestic violence, at a hospital efforts are made to document all of the injuries. The consultant may call on a dentist to assist with the examination and recovery of bite mark evidence if such injuries are found. Dental practitioners should be sufficiently familiar with the necessary procedures to assist the consultant in this way. Obviously, other authorities may also request such involvement in cases of violent interpersonal crimes in the dentist's local jurisdiction. 


\section{Typical presentation of bitemark injuries}

Human bitemarks are most often found on the skin of victims, and they may be found on almost all parts of the human body. Females are most often bitten on the breasts and legs during sexual attacks, whereas bites on males are commonly seen on the arms and shoulders. ${ }^{5,6}$ In defensive circumstances, as when the arms are held up to ward off an attacker, the arms and hands are often bitten.

A representative human bite is described as an elliptical or circular injury that records the specific characteristics of the teeth. ${ }^{7}$ The injury may be shaped like a doughnut with characteristics recorded around the perimeter of the mark. Alternatively, it may be composed of two U-shaped arches that are separated at their bases by an open space. The diameter of the injury typically ranges from $25-40 \mathrm{~mm}$. Often a central area of bruising can be seen within the marks from the teeth. This extravascular bleeding is caused by pressure from the teeth as they compress the tissue inward from the perimeter of the mark.

Bitemarks with high evidentiary value that can be used in comparisons with the suspects' teeth will include marks from specific teeth that accurately record distinct traits (see figure 1). It is possible to identify specific types of teeth by their class characteristics. For example, incisors produce rectangular injuries and canines produce triangular injuries. But it is necessary to have individual characteristics recorded in the bitemark to be able to identify positively the perpetrator. Use, misuse and abuse of the teeth result in unique features that are referred to as accidental or individual traits. Such characteristics include fractures, rotations, attritional wear, congenital malformations, etc. When these are recorded in the injury it may be possible to compare them to identify the specific teeth (person) that caused the injury. If these individual characteristics are not present in the teeth, or if they are not recorded well in the injury, the overall forensic significance of the bitemark is reduced. ${ }^{8}$

The injuries caused by teeth can range from bruises to scrapes and cuts or lacerations. Certainly, it is possible for enough force to be generated to allow penetration of
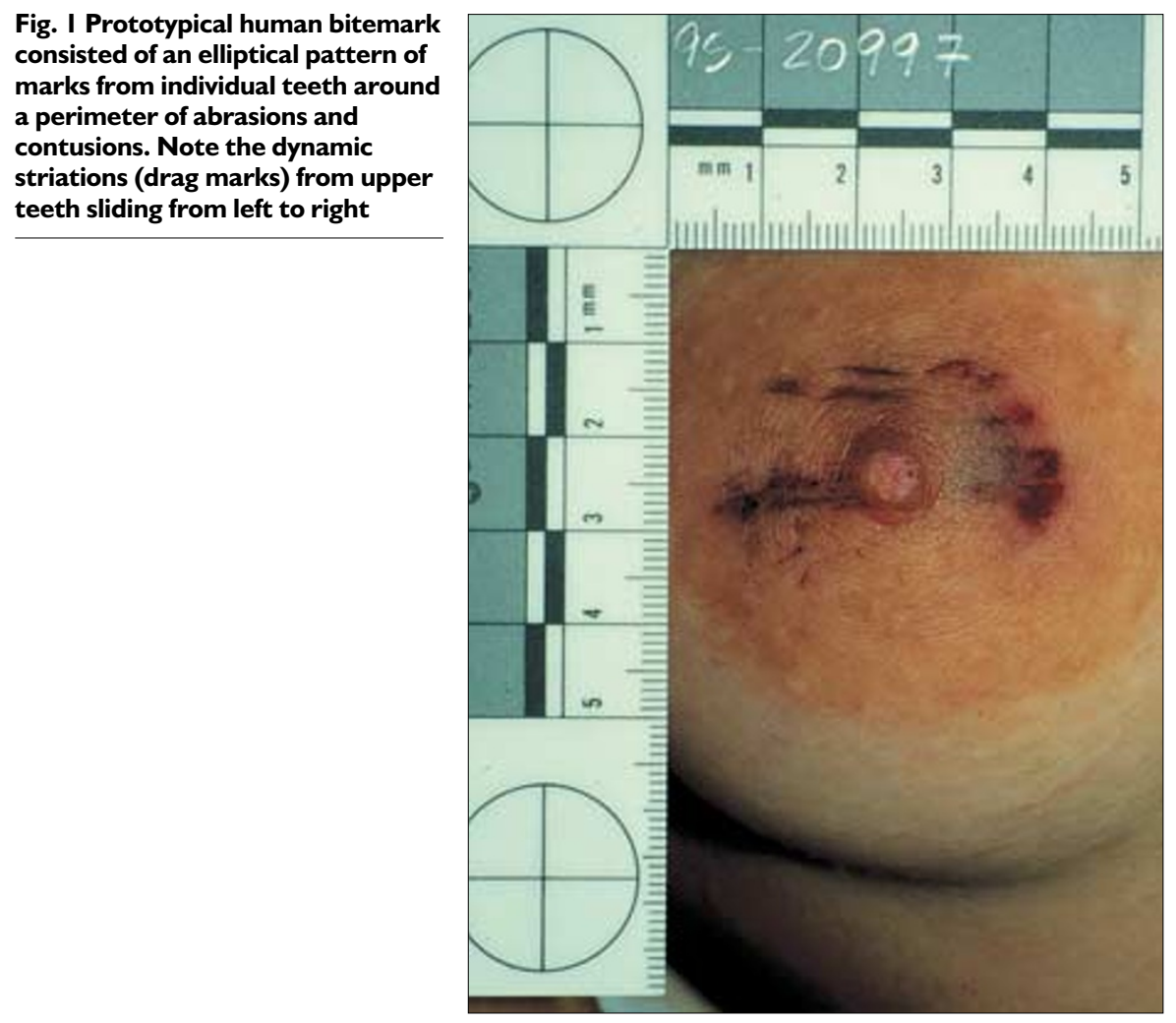

the biting edges of the teeth into the deep layers of the skin. If much time elapses from the moment of injury to the time of discovery, the diffuse nature of bruises and the changes associated with injuries over a period of time may further diminish the evidentiary value. This is especially true in the case of living bite victims but also in deceased individuals.

It is very important during initial examination of the injury to be certain that an artefact, such as an ECG electrode applied by emergency medical personnel, did not cause the pattern or that some object other than teeth has caused a circular or elliptical injury. The authors have witnessed burns from the end of a hair curling iron and patterns from the end of a lead pipe that closely resembled bitemarks. These could be differentiated by the absence of class characteristics caused by human teeth in each case.

\section{Evidence collection from the bite victim}

The dentist in private general practice does not often have the opportunity to deal with procedures for collecting evidence from bite victims. Detectives at the scene of the crime, pathologists at autopsy or medical personnel in the emergency suite find most bites. But since physical and biological evidence from a bitemark begins to deteriorate soon after the bite is inflicted, all dentists should be familiar with the general principles of evidence collection. This is especially true for dentists that deal with patient popula- tions that may potentially contain victims of domestic violence, in which bites are often discovered. ${ }^{6}$ Practitioners should make every effort to accurately and precisely preserve the evidence as soon as it is discovered using the following techniques, and not wait until others with more experience can be consulted or summoned. The best or only opportunity to collect the evidence may be when it is first presented and observed.

If a dentist finds a patterned injury that is suspected to be a bitemark, it should be reported to the police or social welfare agency with local jurisdiction. Then, the dentist should complete the following list of procedures to properly collect the evidence:

\section{Documentation}

Make a record of the injury, including descriptive, narrative notes that document entation of the injury. ${ }^{9}$ What is the location on the body? What is the relative contour and elasticity of the site? Can the difference between marks from the upper and lower teeth be determined? What types of injuries are present? Cuts? Bruises? Scrapes?

\section{Photographs}

Take extensive orientation and close-up photographs using an intra-oral camera with a macro lens and both colour and black-and-white film. A reference scale, such as a ruler, should be placed in the same plane as the injury and visible in the photographs to enable subsequent measurethe physical appearance, colour, size and ori- 
ments. Be certain that the camera is positioned directly over the injury site. The long axis of the lens should be perpendicular to the bitten skin to reduce perspective distortion in the photographs. ${ }^{9}$

\section{Saliva swabs}

Saliva will have been deposited on the skin during biting or sucking and this should be collected and analyzed. Use the double swab technique: ${ }^{10}$ first, a cotton swab moistened with distilled water is employed to wash the surface that was contacted by the tongue and lips using light pressure and circular motions. Then, a second swab that is dry is used to collect the remaining moisture that is left on the skin by the first swab. Both swabs are thoroughly air-dried at room temperature for at least 45 minutes before they are released to police authorities for testing.

The two swabs must be kept cool and dry to reduce the degradation of salivary DNA evidence and the growth of bacteria that may contaminate the samples and reduce their forensic value. Then they should be submitted to the laboratory as soon as possible for analysis. If the time until submission is protracted, it is recommended that the swabs be stored in a paper evidence envelope or box that will allow air to continue to circulate around the swab tips. (The swabs should not be sealed in plastic bags or plastic containers.) The envelopes or boxes should be refrigerated or frozen during storage.

A DNA sample must also be collected from the victim at this time to provide the opportunity for comparison with the sample from the bitemark. This sample could consist of a buccal swab or a sample of whole blood. The victim's DNA profile will enable analysis of any mixtures that are found in the sample from the bite, which may involve contributions from the depositor and the victim.

\section{Impression}

Fabricate an accurate impression of the bitten surface to record any irregularities produced by the teeth, such as cuts, abrasions, etc. Use vinyl polysiloxane, polyether or other impression material available in the dental office that is recommended for fixed prosthetic applications. ${ }^{7}$ Dental acrylic or plaster can be used as a rigid support for the impression material. This will allow the impression to accurately record the curvature of the skin.

\section{First aid}

Prompt medical attention should be provided for the living victim since human bites have a higher potential for infection than animal bites. ${ }^{11}$ Injuries that disrupt the integrity of the skin's surface should be treated as soon as possible.

\section{Evidence collection from the bite suspect}

The collection of dental exhibits for forensic uses has been deemed to be an invasive procedure. Thus, dental impressions and bite samples that are seized from a suspect are susceptible to strict rules of evidence. ${ }^{9}$ They must be obtained either using a court order (warrant) or with a signed and witnessed informed consent. North American Courts have ruled that collection of this type of evidence does not violate the individual's rights against self-incrimination because he is not being required to testify against himself, only to provide physical evidence that will be used in a comparison. If the suspect refuses to provide exhibits for comparison purposes, he may be held in contempt until he complies. The Court might issue an order in this instance to authorize the use of force to obtain the exhibits. In the United Kingdom, court orders are not available to collect evidence by force. A jury is left to develop their own conclusions if the suspect refuses to submit to dental evidence collection procedures. For a detailed account of the warrant issue within the UK (excluding Scotland) readers should consult the Police and Criminal Evidence Act (PACE).

In the authors' experience, suspects are usually quite co-operative during the collection of physical exhibits. However, this is not always the case and so the dentist who is requested to assist authorities to collect evidence should see that provisions to ensure their personal security are in place.

Most commonly, the suspect is in custody and the dental examination takes place away from the practitioner's dental office, perhaps in a jail or remand facility. Police will usually provide transportation to and from the site and provide assistance to the dentist with respect to moving and setting up any equipment and supplies that are needed for the examination. The following exhibits and items of physical evidence are recovered during examination of the bitemark suspect:

\section{Clinical examination}

The extra-oral and intra-oral structures are examined and significant findings are noted on a dental chart. Special attention is focused on the status of the general dental health, occlusion and mandibular articulation. ${ }^{12}$ Results of a specific examination of such things as tooth mobility, periodontal pocketing, dental charting of restorations, diastemata, fractures, caries, etc., and the function of masticatory muscles are documented.

\section{Photographs}

Full facial and profile photographs are produced in addition to intra-oral exposures to depict the upper and lower dental arches and frontal and lateral views of the teeth in occlusion. ${ }^{13} \mathrm{~A}$ reference scale to enable measurements to be taken from the photographs should be included in the same plane as the teeth.

\section{Impressions}

It is necessary to produce extremely accurate study casts of the teeth that record all of the physical traits and characteristics of the dentition. Accurate dental impression materials, such as vinyl polysiloxane or polyether should be used, although custom special trays are seldom fabricated for the suspect. It is recommended that two sets of study casts be produced using a hard stone, such as dental die stone. ${ }^{9}$ All of the materials, including the trays, impressions and casts are maintained in secure storage for eventual release to police authorities. The specific instructions for product handling and material mixing that are recommended by the manufacturer must be closely followed.

\section{Bite sample}

A sample of the suspect's bite is recorded in centric occlusion using either a wafer of baseplate wax or a sample of silicone putty 
material designed for this purpose. ${ }^{9}$ This exhibit should be photographed immediately after it is recorded. This will provide an opportunity for future comparison of the photograph and the exhibit to verify that no distortion has occurred. The suspect should be held in custody until the quality and accuracy of all of the exhibits is determined to be satisfactory.

\section{Forensic physical comparison of exhibits}

The most common methods to determine if the suspect's teeth caused the bitemark include techniques to compare the pattern of the teeth (shape, size, position of teeth, individually and collectively) with similar traits and characteristics present in life-sized photographs of the injury using transparent overlays. These overlays have been produced using various techniques. ${ }^{14}$ The most accurate technique has been found to be a method using a computer. ${ }^{15}$ Other comparison methods include the direct comparison of the suspect's study casts with photographs of the bitemark, comparison of test bites produced from the suspect's teeth with the actual bitemark, and the use of radiographic imaging ${ }^{16}$ and scanning electron microscopy. ${ }^{17}$

Some effort has been made to standardize the comparison procedures but, unfortunately, the conclusions are often based on the expert's level of personal experience and judgement. ${ }^{18}$ The American Board of Forensic Odontology has worked hard to establish guidelines for independent examination of the same evidence by second and third odontologists before the primary expert submits a final report. Regardless, many cases have been disputed because of differing expert opinions, attacks on the scientific basis of physical comparisons because of the elasticity of skin and the question of uniqueness of the human dentition. ${ }^{12}$

\section{Human bites as forensic biological evidence}

During the process of biting and also during kissing and sucking, saliva is deposited on the skin's surface. It has been shown that this trace evidence is present in sufficient quantity and quality to enable PCR-based typing of the DNA that is present in saliva from white blood cells and possibly from sloughed epithelial cells. ${ }^{19}$ Significantly, since highintensity alternative light sources and lasers are now widely used by the police to locate stains from bodily fluids at the crime scene, saliva stains deposited on skin - even in the absence of marks from teeth — can be found and recovered. After analyzing the salivary DNA and establishing the depositor's DNA profile, this result can be compared with the DNA profile of any suspects obtained from buccal swabs containing saliva or whole blood taken using a lancet. ${ }^{20}$

The double swab technique has proven to be an effective method to obtain this salivary evidence from both skin and inanimate objects. ${ }^{20,21}$ Using this technique it has been shown that the DNA profile from the victim's skin can be differentiated from the DNA profile of the saliva contributor. If the DNA profile obtained from the bitemark matches the DNA profile of the suspect there are only two possible explanations for how this might happen. Either the suspect is the depositor or someone else possessing the identical DNA profile deposited the saliva. To evaluate the likelihood of this second scenario, calculations are completed to evaluate how rare or common the profile is in the general population. ${ }^{22}$

\section{Summary}

Conclusions from the analysis of bitemark evidence can assist the justice system to answer crucial questions about interactions between people at the scene of a crime. Willingness by dentists to recognize, collect and preserve this evidence can be invaluable in the resolution of heinous interpersonal crimes.

The authors gratefully acknowledge the suggestion of Dr. David Kennedy, Vancouver, Canada to submit this manuscript to the British Dental Journal for publication.

1. Furness J. A general review of bite-mark evidence. Am J Forensic Med Pathol 1981; 2: 49-52.

2. Webb D A, Pretty I A, Sweet D. Bitemarks: $a$ psychological approach. Proceedings of the American Academy of Forensic Sciences Reno, NV, February 2000; 6: 147.

3. Vale G L. Dentistry, bitemarks, and the investigation of crime. J Calif Dent Assoc 1996; 24: 29-34.

4. Tsang A, Sweet D. Detecting child abuse and neglect - Are dentists doing enough? J Can Dent Assoc 1999; 65: 387-391.

5. Vale G L, Noguchi T T. Anatomical distribution of human bitemarks in a series of 67 cases. $J$ Forensic Sci 1983; 28: 61-69.

6. Pretty I A, Sweet D. Anatomical locations of bitemarks and associated findings in 101 cases from the United States. J Forensic Sci 2000; 45: 812-814.

7. American Board of Forensic Odontology. ABFO Guidelines and Standards. In Bowers C M, Bell G L (ed) Manual of Forensic Odontology. 3rd ed. pp299, 334-353. Colorado Springs: American Society of Forensic Odontology, 1995.

8. Rothwell B R. Bitemarks in forensic odontology: Fact or fiction? In Worthington P, Evans J R (ed) Controversies in Oral and Maxillofacial Surgery. pp588-600. Philadelphia: WB Saunders Company, 1994.

9. Sweet D. Human bitemarks: examination, recovery and analysis. In Bowers C M, Bell G L (ed) Manual of Forensic Odontology. 3rd ed. pp148-170. Colorado Springs: American Society of Forensic Odontology, 1995.

10. Sweet D, Lorente J A, Lorente M, Valenzuela A, Villanueva E. An improved method to recover saliva from human skin: the double swab technique. J Forensic Sci 1997; 42: 320-322.

11. Pretty I A, Anderson G S, Sweet D. Human bites and the risk of HIV infection. Am J Forensic Med Pathol 1999; 20: 232-239.

12. Pretty I A. Bitemark overlays - an analysis of effectiveness. Masters thesis. Vancouver: University of British Columbia, March 2000.

13. Sweet D, LeRoy H A. Human bitemarks Recovery of forensic evidence from suspects. RCMP Gazette 1996; 58: 2-7.

14. Sweet D, Bowers C M. Accuracy of bitemark overlays: a comparison of five common methods to produce exemplars from a suspect's dentition. J Forensic Sci 1998; 43: 362-367.

15. Sweet D, Parhar M, Wood R E. Computerbased production of bitemark overlays. J Forensic Sci 1998; 43: 1046-1051.

16. Rawson R D, Bell A, Kinard B S, Kinard J G. Radiographic interpretation of contrastmedia-enhanced bitemarks. J Forensic Sci 1979; 24: 898-901.

17. David T J. Adjunctive use of scanning electron microscopy in bitemark analysis: a 3-D study $J$ Forensic Sci 1986; 31: 1126-1134.

18. Rothwell B R. Bitemarks in forensic dentistry: a review of legal and scientific issues. JADA 1995; 126: 223-232.

19. Sweet D, Lorente J A, Lorente M, Valenzuela A, Villanueva E. PCR-based typing of DNA from saliva recovered from human skin. J Forensic Sci 1997; 42: 447-451.

20. Sweet D, Hildebrand D P. Saliva from cheese bite yields DNA profile of burglar: a case report Intl J Legal Med 1999; 112: 201-203.

21. Sweet D, Shutler G G. Analysis of salivary DNA evidence from a bitemark on a submerged body. J Forensic Sci 1999; 44: 1069-1072.

22. Shoemaker J S, Painter I S, Weir B S. Bayesian statistics in genetics: a guide for the uninitiated [Review] Trends Genet 1999; 15: 354-358. 